\title{
Erratum to: Molecular characterization, expression profiles of the ovine FSHR gene and its association with litter size
}

\author{
Xiangyu Pan · Shijia Liu $\cdot$ Fadi Li $\cdot$ \\ Weimin Wang $\cdot$ Chong Li $\cdot$ Youji Ma • \\ Tingfu Li
}

Published online: 30 September 2014

(C) Springer Science+Business Media Dordrecht 2014

\section{Erratum to: Mol Biol Rep}

\section{DOI 10.1007/s11033-014-3666-8}

In the original version of this paper, we unfortunately marked a wrong address for correspondence, but the correct address for correspondence should be College of Animal Science and Technology, Gansu Agriculture University, Lanzhou, 730000, People's Republic of China. The correct address for correspondence also appears above.

The online version of the original article can be found under doi:10.1007/s11033-014-3666-8.

X. Pan · S. Liu · F. Li · W. Wang $(\bowtie) \cdot$ C. Li · Y. Ma College of Animal Science and Technology, Gansu Agriculture University, Lanzhou 730000, People's Republic of China e-mail:wangwm@gsau.edu.cn

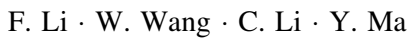

Engineering Laboratory of Sheep Breeding and Reproduction Biotechnology in Gansu Province, Minqin 733300, People's Republic of China

T. $\mathrm{Li}$

Minqin Zhongtian Sheep Industry Co. Ltd, Minqin 733300,

People's Republic of China 